\title{
Effect of an In-Service Care Training on Performance of Working Personnel in Assisted Living Facilities in Damanhour
}

\author{
Hanaa Shafik Ibrahim, Assisatnt Professor \\ Gerontological Nursing, Faculty of Nursing, Alexandria University \\ Magda El Gameel, Lecturer \\ Gerontological Nursing, Faculty of Nursing, Damanhour University
}

\begin{abstract}
Frequent guidance and training of working personnel is essential in order to update their knowledge and improve their skills in dealing with elders in assisted living facilities. Objective: The aim of the study is to determine the effect of a structured in-service care training on performance of working personnel in Assisted Living Facilities. Setting: The study was carried out in Dar El Almogamae Dar Elmossenin and Dar El Sadaa in Damanhour. Subjects: All working personnel in the previously mentioned settings were included in the study. Their number amounted to 45. Tools: Two tools were used: Socio-demographic and Clinical Data Structured Interview Schedule, and an observation checklist. Results: Performance of working personnel after the implementation of the training program improved significantly. The main factors associated with their good performance were age, and attendance of previous training program. Conclusion: The structured in- service care training had a significant and positive effect on performance of working personnel in Assisted Living Facilities in Damanhour. Recommendations: In- service care training for all working personnel in Assisted Living Facilities in Damanhour is important to be scheduled periodically about elderly care in order to update their knowledge and improve their practice.
\end{abstract}

Keywords: Caregivers; Elders, Care Training; Assisted Living Facilities.

\section{Introduction}

Assisted Living Facilities are residential options for elderly persons. They are important shelters for those who have no one to care for, no place to live in or need assistance in performing activities of daily living and for social interaction and safety. Assisted Living Facilities may be considered an intermediate between independent living and nursing homes ${ }^{(1,2)}$.

Moving to an elderly home is always stressful. Some elders need more time to adjust and cope with this transition. So, the working personnel in these homes play an important role in meeting the elders' needs and help them to cope with this transition or relocation $^{(3)}$. They should orient the newly admitted elderly about the home settings. This includes the different rooms such as bed rooms, living and dining rooms, toilets, kitchen, roommates. Also, they should inform him about the services offered by home. Working personnel are the persons who keep in contact with the residents several hours/day, meeting their needs, dealing with or conveying their complaints, problems or needs to the administrative staff. In addition to the role of working personnel in encouraging the elders to share in different activities either inside and/or outside the home. Also, working personnel play an important role in monitoring elders' physical health and well-being in order to apply measures to meet their needs whether physical, psychological or social ${ }^{(4,5)}$.

Poor care will have a negative impact on elders' health and their coping with the changes associated with the aging process and the relocation stress syndrome. This may trigger different problems over all the health dimensions of the elders either physical, psychological or social ${ }^{(6)}$. This impact may be magnified especially in rural areas where elderly homes have limited 
resources and unskilled and unqualified working personnel to provide the care.

In Damanhour, two studies conducted in elderly homes reported that the majority of residents of these homes have poor oral health and poor foot care ${ }^{(7,8)}$. This denotes that working personnel are unprepared for their role and throw light on their urgent need for training about the importance of hygienic care and other aspects of physical and psychological care. Education, training, guidance and supervision of working personnel during their work is essential in order to provide high quality care to the residents. This in turn, will improve elders' health and their ability to cope with the changes associated with aging process and attain a successful aging. As well as avoiding psychological or social problems that may threaten elders' health and may lead to morbidity and accelerate mortality ${ }^{(9)}$.

\section{Aim of the Study}

The aim of this study is to determine the effect of a structured in-service care training on performance of working personnel in Assisted Living Facilities in Damanhour.

\section{Research Hypothesis:}

The performance of working personnel will improve after implementing a structured in-service care training than before.

\section{Materials and Method}

\section{Materials}

Design: A pre- experimental research design was used in this study (one group pre and post test).

Setting: The study was carried out in the two assisted living facilities available in Damanhour city, Beheira Governorate namely Dar El Almogamae Dar Elmossenin which is a governmental home and Dar El Sadaa which is a private one.

1. Almogamae Dar Elmossenin includes three residential homes namely; Dar ElHanan, Dar El-Hanaand Dar El-Amal, with a total number of 50 residents. These are cared for by 20 working personnel. Among the criteria for admission to these homes are elders aged 60 years and more, independent and ambulant.

2. Dar El-Saada consists of three floors with a total number of 40 residents. These elders are cared for by 25 working personnel. Among the criteria for admission to this home are elders aged 60 years and more, partially or completely dependent.

Subjects: All working personnel (managers, social workers, dietary supervisors, and Care providers) in the previously mentioned settings were included in the study. Their number amounted to 45 .

\section{Tools:}

Tool I: Working personnel Socio demographic and Clinical Data Structured Interview Schedule

This tool was developed by the researchers based on relevant literatures and included the following items:

a. Socio demographic characteristics of working personnel such as age, sex, social status and level of education.

b. Occupation profile as type of work, years of experience, working hours, attendance of any previous training program and difficulties encountered in dealing with elderly persons.

\section{Tool II: Observation Checklist}

This checklist was developed by Abd Elgalil $(2005)^{(10)}$. It is used to monitor the care provided by working personnel to the residents. The tool is valid and reliable $\mathrm{r}=0.83$. It includes items related to each job assumed by personnel in Assisted Living Facilities. The check list is a 3 point Likert scale with no score 1 , yes score 2 and not applicable 3 .

Items related to care providers; observed items include 75 items related to:

a- Communication effectively with elders (10 items). 
b- Providing direct daily care (57 items): This part includes seven subcategories such as, elderly' nutrition (9 items), hygienic care (9 items), elimination (3 items), physical activity (3 items), elders' safety (11 items), care of bedridden elderly (16 items), and social needs of elderly (6items).

c- Signs \&Symptoms of abuse and neglect of elderly residents (8 items).

Items related to social workers: include 28 items related to communication (10 items), the role of social worker in Assisted Living Facilities (14 items) such as interviewing the elders on admission, investigate the social status of elders, registration, and schedule recreational activities and abuse and neglect of elderly residents (4 items).

Items related to dietitian include 13 items related to communication with elders (10 items), and the role of dietitian in preparing food (3 items).

Items related to managers include 13 items related to communication (10 items), and elders' abuse (3 items).

The total practice score is 100 and is divided into three categories;

- Poor practice: total score less than 50\%.

- Fair practice: total score ranging from 50$69 \%$.

- Good practice: total score equal to $70 \%$ and more.

\section{Method}

- Official letters were issued from the Faculty of Nursing, Damanhour University to the director of each elderly home to carry out the study.

- Approval of the director of each elderly home was obtained after explanation of the purpose of the study.

- The director of each home was informed about the date and time of data collection.
- The study tool I socio-demographic structured interview schedule was developed by the researchers and was tested for the content validity by three jury experts in Gerontological Nursing in Alexandria University.

- A pilot study was carried out on seven care givers in Dar El-Hana in Alexandria; they were chosen randomly to test clarity of the tools and in order to determine the approximate time needed for each interview. The necessary modifications were done.

- A list of all working personnel in each of the elderly homes in Damanhour was obtained from the directors. Then, participants were interviewed individually in their working place to collect the data using tool I.

- All working personnel in Almogamae Dar Elmossenin and Dar El-Saada and involved in the care of the elderly persons were observed by the researchers every 30 minutes to assess and record their performance over a period of six consecutive working days during morning and afternoon shifts i.e. from 8 am to $2 \mathrm{pm}$ and $2 \mathrm{pm}$ to $8 \mathrm{pm}$ respectively.

- The proposed structured in-service care training:

The care training was developed by the researchers based on working personnel's needs which was determined through assessing their knowledge and their observation during their actual work with the residents. The results of the preassessment revealed lack of knowledge of the working personnel about communication, maintaining ethics and rights of the residents, normal age related changes, care of bedridden elders, nutrition for healthy and sick elders, measures to improve cognitive function of elders, abusive and negligence behaviors and 
application of safety measures. The care training was implemented in 8 sessions, two sessions per week:

- Session I: Normal age related changes (physical \&
psychosocial changes):

In this session, the researchers used video to illustrate the normal changes associated with aging whether physical, psychological or social and its impact on their life, behaviors and reactions. Also, how to differentiate between the normal and abnormal changes. The time of session ranged from 45 to 60 minutes.

\section{- Session II: Ethics and older adults' rights:}

This session included items related to importance of respecting and maintaining residents' privacy, encouraging elders to express their feelings, discuss elders' needs, and problems confidently and help them to attain appropriate solutions or decisions. Maintain safety by protecting residents from environmental hazards and Encourage the elderly persons to take proper decision by themselves. In this session, the researchers used to demonstrate some behaviors denoting negligence and abuse of elders through role playing e.g. shouting, pushing, or grasping the elders hardly. This session lasts 60 minutes.

\section{- Session III: Communication:}

In this session, the researchers discussed with the participants the principles and techniques of effective communication with normal elders and those with visual or hearing impairment. Also, the factors hindering communication with the residents. Simulation was used to help the working personnel identify factors that hinder communication and how to overcome them. The time of this session ranged from 30 to 60 minutes.

\section{- Session IV: Cognitive stimulation for elders:}

In this session the researchers focused on measures to improve elders' cognitive function such as avoid elders' loneliness, encourage participation in group activities, and share in games e.g. mathematic calculations, cross words, and chess. Application of reminiscence therapy techniques was done in this session. This session' time ranged from 30 to 45 minutes.

\section{- Session V and VI: care of bed ridden elders:}

In these sessions, the researchers demonstrated hygienic care for residents and for those who are bedridden emphasizing the importance of foot and skin care especially for those suffering from D.M, and measures to prevent complications among immobile elders such as frequent change of position and range of motion exercises. As for incontinent elders, teaching was given about changing wet clothes, toilet training, and fluid intake. Videos and demonstration and re-demonstration were used to illustrate these measures. The time of the two sessions ranged from 90 to 120 minutes.

\section{- Session VII: Nutrition for elders:}

This session included factors affecting food intake, type of diet ordinary and therapeutic, preparation of healthy food and offering food. The researchers gave example of different types of diet. The time of this session was 30 to 45 minutes.

\section{- Session VIII: Safety measures:}

In this session, the researchers discussed the importance of safety measures for elders whether personal or environmental as adequate light, keep always floors dry, help elders get 
up slowly and provide elders with suitable clothes. Videos and Role play were used. The time of the session ranged from 45 to 60 minutes.

- At the beginning of each session, the researcher revised what was discussed in the previous sessions and after each session, the researcher summarized the important points discussed in the session, then time was given to questions and discussions.

\section{- Evaluation of the care training:}

After the implementation of care training, each participant was observed by the researchers every 30 minutes during their actual work with the elders and recorded their performance in the observation checklist.

- Data were collected during a period of three months starting from first January 2017 to the end of March 2017.

\section{Ethical considerations:}

Verbal consent was obtained from each working personnel after explaining the purpose of the study. Privacy was maintained during the process of data collection. Confidentiality of the collected data and anonymity were guaranteed.

\section{Statistical Analysis}

Data were fed to the computer and analyzed using IBM SPSS software package version 20.0. (Armonk, NY: IBM Corp) Qualitative data were described using number and percent. Significance of the obtained results was judged at the $5 \%$ level.

\section{The used tests were:}

\section{1- Chi-square test:}

For categorical variables, to compare between different groups.

\section{2- Monte Carlo correction:}

Correction for chi-square when more than $20 \%$ of the cells have expected count less than 5 .

\section{Results}

Table (1) shows the socio-demographic characteristics of the working personnel. The age of the studied subjects ranged from 20 to 55 years with a mean age $40.76 \pm 6.42$. Females constituted $86.7 \%$ of the working personnel and the rest $13.3 \%$ were males. The majority $84.5 \%$ were married.

Regarding education, of $35.6 \%$ of working personnel were illiterates, $37.8 \%$ with basic education and $24.4 \%$ had secondary school education. Only one $2.2 \%$ had a university degree.

Table (2) illustrates occupation profile. The main job assumed by working personnel in Assisted Living Facilities was either direct care providers $62.1 \%$; social workers $22.2 \%$, or dietitian $11.1 \%$ and two Managers $(4.4 \%)$.

Regarding the years of experience in dealing with elders, $73.3 \%$ of working personnel reported ten years and more, $20.0 \%$ five to less than ten years and $6.6 \%$ less than five years.

Concerning attendance of any training program about elders' care, only35.5\% attended one training program and the rest did not.

Table (3) shows the difficulties reported by working personnel to affect their care were mostly related to elders' rigidity $86.6 \%$. This affected not only the care but also hindered effective communication with them. Inadequate resources and workload were reported by $71.1 \%$ and shortage of care providers by $55.5 \%$.

Table (4) illustrates the effect of the structured in-service care training on performance of working personnel in assisted living facilities. Care providers were observed during providing care to the residents. This included way of communication with the elderly person, feeding, hygiene, elimination, encourage physical activity, safety, social needs of elders, care of bedridden elders and negligence or abuse of the elderly residents. 
For all items of direct care, poor practice of care providers was observed in all the studied items pre-care training while after the care training their practice increased significantly in all the items. Negligence is an important item of care, the table shows that $89.2 \%$ of care providers used to neglect or abuse some elders pre training compared to $10.7 \%$ post care training program. A significant difference was noted $\mathrm{P}=<0.001$.

For social workers, communication with the elderly person and the role of social worker in assisted living facilities including interviewing elders on admission, investigate the social status of elders, registration, and schedule recreational activities were the observed items.

Poor communication with elders was practiced by $90 \%$ pre care training compared to $0.0 \%$ post training. In relation to the role of social worker in assisted living facilities, poor practice was observed among $80 \%$ pre training compared to $0.0 \%$ post training. Also, negligence of elders was observed among $60 \%$ of social workers pre training compared to $10 \%$ post training. A significant relation was noted $\mathrm{P}=<0.002$.

For dietitian, establishing good relation with elders and teaching them about their diet and listen to their complaints are essential aspects of their practice. Poor practice was observed in $80 \%$ pre training compared to $0.0 \%$ post training with a statistically significant relation $\mathrm{P}=<0.001$.

For managers, listening to elders' complaints and supervising the different activities performed in assisted living facilities, environmental safety and monitoring performance of working personnel. The table shows that the care training improved significantly their role $\mathrm{P}=<0.001$.

Table (5) shows the main factors affecting elderly care. Attending of previous training program affected significantly care provided to the elders $\mathrm{P}=<0.007$ and decreased of negligence or abuse $\mathrm{P}=<0.002$.
As well, age of working personnel affected significantly the care provided to the elders $\mathrm{P}=<0.041$.

\section{Discussion}

Caregiving for older adults is a broad scope that involves providing all types of care and assistance starting from meeting the basic needs to improve health and welfare of older adults. Although, caregiving may be a source of stress for caregivers, yet it has different advantages as it enhances self esteem\& wellbeing, personal growth\& satisfaction of caregiver and finding a meaning through caregiving ${ }^{(9)}$. This can be attained if the caregivers are more knowledgeable about elderly care which enable them to be creative in dealing with the different challenges associated with aging process. The situation may be difficult in rural areas where the era of admission to assisted living facilities is new, and unusual trend. In addition, these settings may not be well prepared in their resources to meet the needs of older adults. In Damanhour, there are only two Assisted Living Facilities, one is governmental which includes ambulant elders and the other is private that is specialized for bedridden elders.

Improving health care provided to elders need to be addressed at these Assisted Living Facilities. One way to address this issue is to implement in-service training programs and educate working personnel to help them provide the best care for their residents ${ }^{(3)}$.So, the aim of this study is to determine the effect of a structured inservice care training on performance of working personnel in assisted living facilities. In Alexandria, a study conducted in all governmental elderly homes reported that more than three quarters of the care givers did not receive any training program about elderly care ${ }^{(11)}$. Also, in the present study, nearly two thirds of working personnel did not attend any training program about elderly care (Table 2 ).

The results of this study revealed that care provided to elders significantly 
improved after implementing the care training for working personnel (Table 4).

In other words, the overall practice for all working personnel according to type of assigned job improved after the care training than before. The result of the present study is in accordance with other studies conducted in the United Kingdom which evaluated a structured competency - based training program for caregivers of elderly residents suffering from stroke. It was reported that both physical and psychological care for those elderly patients were improved after the program ${ }^{(12)}$. Also, two studies $2010,2017^{(13,14)}$ conducted in Mansoura University Hospital in neurological department and Oncology center reported that knowledge and practice of all care givers about care of elders suffering from stroke and colorectal cancer improved after implementation of the training program.

Communication with elderly residents is the way to understand the world of elderly resident, establish a trustful relation with them, identify their problems and meet his needs. This can facilitate the care provided to the elders. Also, communication helps the resident to be connected with others and be familiar with his new environment. In the present study, the majority of working personnel had poor communication with their residents (Table 4). Also, two studies carried out in Alexandria 2006, 2009 $9^{(10,15)}$ stated that half of caregivers in all governmental elderly homes communicate poorly with elders and the majority of institutionalized elders had communication problems resulting from mainly vision, hearing and cognitive impairments that lead to difficult communication. Moreover, in the present study, it was reported by the majority of working personnel that elders' rigidity is considered the main difficulty encountered in elderly's care and hindering communication (Table 3). So, the care training emphasized on the measures to overcome elders' rigidity through giving them choices and alternatives to help them make decision by themselves without either pushing, rejecting or insisting that may block the communication and lead to more rigidity. Also, the researchers discussed with the working personnel the techniques for effective communication with normal elders and those with visual, hearing and cognitive impairments.

A marked improvement in working personnel's communication with elders after the care training was observed (Table 4). This result is in accordance with other study conducted in U.S.A which revealed high communication skills for nursing aides after the training ${ }^{(16)}$.

Negligence or abuse of elderly residents is a part of working personnel's practice. It is an umbrella which triggered different behaviors as poor communication, lack of elders' hygiene, privacy, nutrition and safety. In the present study, negligence $\&$ abuse of residents constituted $92.8 \%$ pre training in form of calling the residents with unpreferable name, not involving them in decision making, not giving the chance to talk and let them alone (Table 4). In France, elder abuse observed in $20 \%$ in nursing homes or hospitals. The highest number of cases was related to psychological abuse ${ }^{(17)}$. In Alexandria, a study ${ }^{(10)}$ conducted in all governmental elderly homes stated that $56.6 \%$ of care givers do not give elders the chance to talk, hurt their feelings by neglecting to reply \& not listening to elders' talk. The difference between both results may be rationalized as these Assisted Living Facilities in rural areas had lack of resources in spite of shortage of staff and work overload which were reported by most of working personnel as difficulties encountered them in providing care (Table 3). This may induce negligent behaviors for their residents. In the present study, negligence $\&$ abuse of residents were not observed post training and a significant improvement was noted (Table 4). Also, other behaviors observed by the researchers and referring to negligence and abuse of elders were poor or lack of hygiene, 
uncleanliness of elders' utensils and using them without elders' permission. This is in accordance with a study conducted in Alexandria $2000^{(18)}$ in governmental elderly homes stated that poor hygiene, dehydration and not meeting elders' needs were indicators of elders' negligence and abuse. This area of practice improved after the care training (Table 4). The reason for this improvement may be due to prolonged experience with elders and lack of training about elderly care for most of working personnel (Table 2). So, the working personnel were eager to acquire information, apply it in their practice and change their behaviors. Also, unethical treatment with elderly residents as lack of elders' privacy \& safety was another form of negligence and abuse of elders observed in the present study (Table 4). This is supported by two studies conducted in Alexandria ${ }^{(10,18)}$ and recent study carried out in U.S.A, reported that $7 \%$ of cognitively intact older emergency department patients reported a history of physical or psychological abuse during the past year ${ }^{(19)}$.

The present study revealed significant improvement in avoidance of negligence \& abuse either physically or psychologically after implementing the care training (Table 4).

Based on the results of observation of the care provided to the elders before implementing the care training which reported that the majority of working personnel had poor knowledge related to both nutrition and hygienic care for their elderly residents (Table 4). Also, two studies conducted in Alexandria 2004, $2015^{(20,21)}$ stated that half of care givers had poor knowledge about elders' nutrition and hygienic care for elderly residents. So, the contents of the program sessions covered topics related to nutrition and hygienic care particularly for bedridden elders as most of the residents in the private home were bedridden and caring for them is considered a burden for care providers. The practice of care providers and dietitian improved significantly after implementing the care training (Table 4). This is in the same line with other studies ${ }^{(20,21)}$ conducted in Alexandria in governmental elderly homes and stated that the majority of caregivers had good knowledge about proper diet for their elderly residents and hygienic care after implementing an educational program for care givers which had its impact on their practice.

Improve cognitive function of elders, safety measures to prevent falls and the ethics \& the rights of elders are parts of daily practice of care providers. Several studies ${ }^{(22-27)}$ conducted in governmental and private elderly homes in Alexandria reported that most of their residents suffered from cognitive deterioration, incontinence, falls, depression, low self esteem and loneliness. Improving cognitive function of elders is essential for their interaction with others, prevention or delaying what is considered a normal decline in memory with aging (senile forgetfulness) ${ }^{(9)}$ and decrease the occurrence of depression and loneliness. In the care training, the researchers emphasized different ways to stimulate elders' cognitive function through reminiscence therapy ${ }^{(26)}$, mathematics calculation, managing their financial affairs, or participating in recreational activities, spending time in practicing hobbies and interests or social entertainment with other roommates. Also, the researchers focused on the role of social workers in implementing a schedule of activities for spending the spare time, encouraging elders participate in trips, parties and meetings, and discovering elders' hobbies, interests and talents. In the present study, most of working personnel met the social needs of elders after care training with the percent of $82.1 \%$ preprogram compared to $0.00 \%$ post program (Table 4).

Providing safety for the residents is another area of practice that was discussed with the care providers and included items related to early identification of high risk elders, and provide safe environment. Also, 
education about ethics that should be followed in dealing with elderly persons. Moreover, elders' rights for respect, privacy, autonomy, protection from danger and confidentiality of data related to his life were discussed with the care providers.

The present study revealed significant improvement in the application of safety measures (Table 4).

It appeared from the present study that advanced age of working personnel and previous attendance of training program affected significantly the ability of working personnel to provide elderly care. This is in accordance with two studies conducted in Mansoura (2010) and U.S.A (2015) $)^{(13,28)}$. While, the area of negligence \& abuse of elders is affected significantly by previous attendance of training program for working personnel (Table 5).

\section{Conclusion}

It can be concluded from the present study that the implemented working personnel' care training had a significant and positive effect on care provided to the residents in Assisted Living Facilities in Damanhour. The main factors affecting elderly care were advance age of working personnel, and their attendance of previous training programs. While, presence of negligence $\&$ abuse of elders was affected significantly by previous attendance of training program by working personnel.

\section{Recommendations}

Based on the results of the study, the following recommendations are suggested:

- In service training program for all working personnel in all Assisted Living Facilities in Damanhour should be done periodically about elderly care. This will help to update their knowledge and improve their practice while dealing with the residents

- Encourage staff working in these settings to participate in health classes and conferences conducted in these Assisted Living Facilities by staff members of the Faculty of Nursing, Damanhour University about different aspects of elderly care.

- Supervision of working personnel during their work with elders is important in order to evaluate their performance and to provide incentives in case of reward and penalties in case of failure. 
Table (1): Distribution of working personnel in Assisted Living Facilities according to their socio demographic characteristics

\begin{tabular}{|c|c|c|}
\hline Item & $\begin{array}{c}\text { Number } \\
n=45\end{array}$ & $\begin{array}{c}\text { Percent } \\
\%\end{array}$ \\
\hline Age & & \\
\hline Less than 30 years & 3 & 6.6 \\
\hline $30-$ & 25 & 55.5 \\
\hline More than 40 & 17 & 37.7 \\
\hline Mean \pm SD & \multicolumn{2}{|c|}{$40.76 \pm 6.42$} \\
\hline Sex & & \\
\hline Male & 6 & 13.3 \\
\hline Female & 39 & 86.7 \\
\hline \multicolumn{3}{|l|}{ Education } \\
\hline Illiterate & 16 & 35.6 \\
\hline Basic & 17 & 37.8 \\
\hline Secondary & 11 & 24.4 \\
\hline University & 1 & 2.2 \\
\hline \multicolumn{3}{|l|}{ Marital status } \\
\hline Married & 38 & 84.5 \\
\hline Widowed & 5 & 11.1 \\
\hline Divorced & 2 & 4.4 \\
\hline
\end{tabular}


Table (2): Distribution of working personnel in Assisted Living Facilities according to their type of position, years of experience, and attendance of training program

\begin{tabular}{|l|c|c|}
\hline \hline item & $\begin{array}{c}\text { Number } \\
(\mathbf{n = 4 5})\end{array}$ & $\begin{array}{c}\text { Percent } \\
\text { \% }\end{array}$ \\
\hline Care providers & 28 & $62.3 \%$ \\
Social workers & 10 & 22.2 \\
Dietitian & 5 & 11.1 \\
Managers & 2 & 4.4 \\
\hline Experience in years & 3 & 6.6 \\
Less than 5 & 9 & 20.1 \\
$5-$ & 33 & 73.3 \\
$10+$ & 29 & 64.5 \\
\hline Attendance training program & 16 & 35.5 \\
No & & \\
Yes & & \\
\hline
\end{tabular}

Table (3): Distribution of working personnel in Assisted Living Facilities in Damanhour according to difficulties encountered in dealing with elders

\begin{tabular}{|l|c|c|}
\hline \hline Item & Number & $\%$ \\
& $\mathbf{N}=\mathbf{4 5}^{*}$ & \\
\hline Elders' rigidity & 39 & 86.6 \\
Lack of resources & 32 & 71.1 \\
Workload & 32 & 71.1 \\
Shortage of staff & 25 & 55.5 \\
\hline
\end{tabular}

* More than one answer. 
In-Service Care Training and Performance of Working Personnel

Table (4): Distribution of working personnel in Assisted Living Facilities in Damanhour according to their total practice scores before and after implementation of the care training

\begin{tabular}{|c|c|c|c|c|c|c|c|c|c|c|c|c|c|c|c|c|c|}
\hline \multirow{3}{*}{ Personnel } & \multicolumn{8}{|c|}{ Pre program } & \multicolumn{8}{|c|}{ Post program } & \multirow{3}{*}{ Sig. $P$} \\
\hline & \multicolumn{2}{|c|}{ Poor practice } & \multicolumn{2}{|c|}{ Fair practice } & \multicolumn{2}{|c|}{ Good practice } & \multicolumn{2}{|c|}{ Total } & \multicolumn{2}{|c|}{ Poor practice } & \multicolumn{2}{|c|}{ Fair practice } & \multicolumn{2}{|c|}{ Good practice } & \multicolumn{2}{|c|}{ Total } & \\
\hline & $\mathrm{N}_{0}$ & $\%$ & No & $\%$ & $\mathrm{~N}_{0}$ & $\%$ & $\mathrm{~N}_{0}$ & $\%$ & No & $\%$ & No & $\%$ & No & $\%$ & No & $\%$ & \\
\hline \multicolumn{18}{|l|}{ Care providers } \\
\hline \multicolumn{18}{|l|}{ 1-Providing care } \\
\hline Communication & 19 & 67.8 & 9 & 32.2 & 0 & 0.0 & 28 & 100.0 & 0 & 0.0 & 1 & 3.6 & 27 & 96.4 & 28 & 100.0 & $<0.001$ \\
\hline Nutrition & 26 & 92.8 & 0 & 0.0 & 2 & 7.2 & 28 & 100.0 & 0 & 0.0 & 5 & 17.9 & 23 & 82.1 & 28 & 100.0 & $<0.001$ \\
\hline Hygiene & 26 & 92.8 & 0 & 0.0 & 2 & 7.2 & 28 & 100.0 & 0 & 0.0 & 0 & 0.0 & 28 & 100.0 & 28 & 100.0 & $<0.001$ \\
\hline Elimination & 24 & 85.7 & 2 & 7.1 & 2 & 7.2 & 28 & 100.0 & 8 & 28.5 & 13 & 46.5 & 7 & 25.0 & 28 & 100.0 & $<0.001$ \\
\hline Physical activity & 26 & 92.8 & 0 & 0.0 & 2 & 7.2 & 28 & 100.0 & 12 & 42.9 & 11 & 39.2 & 5 & 17.9 & 28 & 100.0 & $<0.001$ \\
\hline Safety & 23 & 53.5 & 3 & 10.7 & 2 & 7.2 & 28 & 100.0 & 1 & 3.6 & 5 & 17.9 & 22 & 78.5 & 28 & 100.0 & $<0.001$ \\
\hline Care of bedridden & 24 & 85.7 & 2 & 7.1 & 2 & 7.2 & 28 & 100.0 & 0 & 0.0 & 11 & 39.2 & 17 & 60.8 & 28 & 100.0 & $<0.001$ \\
\hline Meeting social needs & 24 & 85.7 & 4 & 14.3 & 0 & 0.0 & 28 & 100.0 & 0 & 0.0 & 5 & 17.9 & 23 & 82.1 & 28 & 100.0 & $<0.001$ \\
\hline $\begin{array}{l}\text { 2- Signs of } \\
\text { negligence\& abuse }\end{array}$ & 25 & 89.2 & 1 & 3.6 & 2 & 7.2 & 28 & 100.0 & 3 & 10.7 & 5 & 17.9 & 20 & 71.4 & 28 & 100.0 & $<0.001$ \\
\hline 0verall & 26 & 92.8 & 2 & 7.2 & 0 & 0.0 & 28 & 100.0 & 0 & 0.0 & 1 & 3.6 & 27 & 96.4 & 28 & 100.0 & $<0.001$ \\
\hline \multicolumn{18}{|l|}{ Social workers } \\
\hline \multicolumn{18}{|l|}{ 1-Providing care } \\
\hline Communication & 9 & 90.0 & 1 & 10.0 & 0 & 0.0 & 10 & 100.0 & 0 & 0.0 & 1 & 10.0 & 9 & 90.0 & 10 & 100.0 & $<0.001$ \\
\hline $\begin{array}{l}\text { Role of social worker } \\
\text { in home }\end{array}$ & 8 & 80.0 & 2 & 20.0 & 0 & 0.0 & 10 & 100.0 & 0 & 0.0 & 2 & 20.0 & 8 & 80.0 & 10 & 100.0 & $<0.001$ \\
\hline $\begin{array}{l}\text { 2- Signs of } \\
\text { negligence\& abuse }\end{array}$ & 6 & 60.0 & 0 & 0.0 & 4 & 40.0 & 10 & 100.0 & 1 & 10.0 & 1 & 10.0 & 8 & 80.0 & 10 & 100.0 & 0.022 \\
\hline Overall & 10 & 100.0 & 0 & 0.0 & 0 & 0.0 & 10 & 100.0 & 0 & 0.0 & 2 & 20.0 & 8 & 80.0 & 10 & 100.0 & 0.022 \\
\hline \multicolumn{18}{|l|}{ Dietitian } \\
\hline \multicolumn{18}{|l|}{ 1-Providing care } \\
\hline Communication & 3 & 60.0 & 1 & 20.0 & 1 & 20.0 & 5 & 100.0 & 0 & 0.0 & 0 & 0.0 & 5 & 100.0 & 5 & 100.0 & 0.021 \\
\hline $\begin{array}{l}\text { Role of dietitian in } \\
\text { home }\end{array}$ & 4 & 80.0 & 1 & 20.0 & 0 & 0.0 & 5 & 100.0 & 0 & 0.0 & 3 & 60.0 & 2 & 40.0 & 5 & 100.0 & 0.001 \\
\hline Overall & 4 & 80.0 & 1 & 20.0 & 0 & 0.0 & 5 & 100.0 & 0 & 0.0 & 0 & 0.0 & 5 & 100.0 & 5 & 100.0 & $<0.001$ \\
\hline \multicolumn{18}{|l|}{ Managers } \\
\hline Communication & 1 & 50.0 & 0 & 0.0 & 1 & 50.0 & 2 & 100.0 & 0 & 0.0 & 0 & 0.0 & 2 & 100.0 & 2 & 100.0 & $<0.001$ \\
\hline $\begin{array}{l}\text { 2- Signs of } \\
\text { negligence\& abuse }\end{array}$ & 0 & 0.0 & 1 & 50.0 & 1 & 50.0 & 2 & 100.0 & 0 & 0.0 & 0 & 0.0 & 2 & 100.0 & 2 & 100.0 & $<0.001$ \\
\hline Overall & 0 & 0.0 & 1 & 50.0 & 1 & 50.0 & 2 & 100.0 & 0 & 0.0 & 0 & 0.0 & 2 & 100.0 & 2 & 100.0 & $<0.001$ \\
\hline
\end{tabular}


Table (5): Significant relation between age and attendance of any training program by working personnel and their performance (in providing care and elders' negligence or abuse)

\begin{tabular}{||l|c|c||}
\hline \multirow{3}{*}{ Variables } & Providing care & Negligence or abuse of elders \\
\cline { 2 - 3 } & Significant tests & Significant tests \\
& P value & P value \\
\hline \multirow{2}{*}{ Age } & $\mathrm{c} 2=8.691^{*}$ & \\
\hline \multirow{2}{*}{ Attendance of programs } & $\mathrm{P}=0.041^{*}$ & $\mathrm{c}^{2}=11.915^{*}$ \\
& $\mathrm{c} 2=9.038^{*}$ & $\mathrm{P}=0.002^{*}$ \\
\hline
\end{tabular}

* Level of significance $\mathrm{P}<0.05$ 


\section{References}

1. Touhy, Jett T. Gerontological Nursing \&Healthy aging. $4^{\text {th }}$ ed. U.S.A: Mosby Company, 2014.

2. Eliopoulos C. Gerontological Nursing. $8^{\text {th }}$ ed. Philadelphia: Lippincott Williams \&Wilkins Company, 2014.

3. Ebersole \& Hess. Toward Health Aging: Human needs \&Nursing responses. $9^{\text {th }}$ ed. U.S.A: Elsevier Inc, 2016.

4. Zulueta E. Roles and Responsibilities of a Caregiver on Elderly Care. Available at: https://senior-care-assistedliving.knoji.com/roles-and-responsibilitiesof-a-caregiver-on-elderly-care/ (Retrieved on: May 2017).

5. Drentea, P. (2007). Caregiving. In: G. Ritzer (Ed.), Blackwell encyclopedia of sociology. Blackwell Publishing. Available at:

http://www.blackwellreference.com/subscri ber/uid $=572 /$ tocnode?query=Caregiving \&w iden $=1 \&$ result_number $=1 \&$ from $=$ search \&f uzzy $=0 \&$ type $=$ std\&id $=\mathrm{g} 9781405124331$ chunk g97814051243319 ss1-7\&slop=1 (Retrieved on: March 2017).

6. Li M, Zhang Y, Zhang Z, Zhang Y, Zhou L, Chen K. Rural-urban differences in the long-term care of the disabled elderly in China. PLoS ONE. 2013; 8(11). Available at:

http://dx.doi.org/10.1371/journal.pone.0079 955 pmid:24224025 (Retrieved on: May 2017).

7. Abed-El-Rahman S. Diabetic foot care program for care givers working in elderly homes in Damanhour. Journal of Modern Arabic Fiction 2013; 10(2):75-90.

8. Bassiouny R. Oral health status of elderly living in residential homes at Damnhour City. Alexandria Scientific Nursing Journal 2015; 16(1): 93-122.

9. Miller C. Nursing for Wellness in Older Adults. $7^{\text {th }}$ ed. New York: Wolters Kluwer Company, 2015.

10. Abd El Galeel A. Attitudes \&Practices of working personnel towards the residents of elderly homes. Unpublished Master Thesis.

Faculty of Nursing, Alexandria University, 2006.

11. Abou El-Soaud H. Effect of support group sessions on stress and burnout of caregivers of institutionalized elderly. Unpublished Doctorate Dissertation. Faculty of Nursing, Alexandria University, 2013

12. Meiner S. Gerontologic Nursing. $5^{\text {th }}$ ed. Philadelphia: El Sevier Mosby Company, 2015.

13. Abd El Hamid S. Care givers' training \& health status outcomes in cerebral stroke elderly patients. Unpublished Doctorate Dissertation. Alexandria University, Faculty of Nursing, 2010.

14. Ali S, Boughdady A, Elkhodary T, Hassnaen A. Effect of refexology training for family care givers on health status of elderly patients with colorectal cancer. International Journal of Nursing Didactics 2017; 7 (9):13-27.

15. Abd El Moneim M. Communication problems among institutionalized elders. Unpublished Master Thesis. Faculty of Nursing, Alexandria University, 2009.

16. Sprangers S, Dijkstra K, Romijn-Luijten A. Communication skills training in a nursing home: effects of a brief intervention on residents and nursing aides. Clinical Interventions in Aging 2015; 10:311-19.

17. Crome P, Moulias R, SánchezCastellano, Tilvis R. Elder abuse in Finland, France, Spain and United Kingdom. European Geriatric Medicine 2014; 5 (4): 277-84.

18. Abd El Monem S, Lachine O. Forms of elderly abuse in residential homes in Alexandria. The New Egyptian Journal of Medicine 2000; 23(5): 219-23.

19. Rosen T,Hargarten S,Flomenbaum N,Timothy F.Identifying Elder Abuse in the Emergency Department: Toward a Multidisciplinary Team-Based Approach. Annals of Emergency Medicine 2016; 68 (3): $378-82$. 
20. Fouad R. Nutritional assessment of elders and development of a nutritional educational program to caregivers. Unpublished Doctorate Dissertation. Faculty of Nursing, Alexandria University, 2004.

21. Gomma H. Effect of care givers' educational program to prevent scabies infection among institutionalized elderly. Unpublished Doctorate Dissertation. Faculty of Nursing, Alexandria University, 2015.

22. Abed El-Rahman A. Effect of institutionalization on the cognitive ability of the elders. Unpublished Master Thesis. Faculty of Nursing, Alexandria University, 2004.

23. Abd El Galeel A. Effect of a behavioral training program on continence outcome for urinary incontinent institutionalized elderly women. Unpublished Doctorate Dissertation. Faculty of Nursing, Alexandria University, 2013.

24. Al-Gameel M. The Effect of Tai Chi Exercise on Balance and fall's incidence among institutionalized elderly. Unpublished Doctorate Dissertation. Faculty of Nursing, Alexandria University, 2013.
25. Shafik H. Effect of Remotivationtherapy on depression among residents of elderly homes. Unpublished Master Thesis. Faculty of Nursing, Alexandria University, 2008.

26. Shafik H. Impact of reminiscence therapy on self esteem among residents of elderly homes. Unpublished Doctorate Dissertation. Faculty of Nursing, Alexandria University, 2004.

27. Lachine O. The effect of nursing intervention program on the loneliness experienced by elderly people. Unpublished Doctorate Dissertation. Higher Institute of Nursing, Alexandria University, 1998.

28. The National Alliance of Care giving \& Public Policy Institute. Care giving in the U.S.A, research report, 2015. 